\title{
Psychometric Properties of The Sub-Health Measurement Scale V1.0 for Assessing Suboptimal Health Status of Midwives: A Multi-Centre Cross- Sectional Study
}

\section{Xiao-Qian Chen}

School of Nursing, Fujian Medical University

Xiu-Min Jiang ( jzc0427@163.com )

Fujian Maternity and Child Health Hospital, Affiliated Hospital of Fujain Medical University https://orcid.org/0000-0003-4133-5301

\section{Qing-Xiang Zheng}

Fujian Maternity and Child Health Hospital, Affiliated Hospital of Fujian Medical University

\section{Xin-Xin Huang}

Fujian Maternity and Child Health Hospital, Affiliated Hospital of Fujian Medical Universty

Gui-Hua Liu

Fujian Maternity and Child Health Hospital, Affiliated Hospital of Fujian Medical University

\section{Yu-Qing Pan}

School of Nursing, Fujian Medical University

\section{Research article}

Keywords: Sub-Health Measurement Scale V1.0, Validity, Reliability, Midwives

Posted Date: July 14th, 2020

DOI: https://doi.org/10.21203/rs.3.rs-41111/v1

License: (c) (i) This work is licensed under a Creative Commons Attribution 4.0 International License. Read Full License 


\section{Abstract}

Purpose Midwives with high work stress are prone to suboptimal health status (SHS). However, there is a lack of unified measurement standard for SHS. Sub-Health Measurement Scale V1.0 (SHMS V1.0) is a multidimensional inventory that has been proved to have adequate psychometric properties in other populations. Therefore, this study aimed to evaluate validity and reliability of SHMS V1.0 in midwives.

Methods In this cross-sectional study, 842 midwives from 46 midwifery institutions completed the SHMS V1.0. Internal consistency and test-retest reliability of SHMS V1.0 were assessed with Cronbach's alpha and Pearson correlation coefficient. Project analysis and confirmatory factor analysis (CFA) were performed to assess construct validity. Concurrent validity of SHMS V1.0 was evaluated by Pearson correlation analysis with the 14-item Fatigue Scale (FS-14).

Results The total Cronbach's alpha and test-retest reliability coefficient of SHMS V1.0 was 0.908 and 0.804 , respectively. The correlation coefficients between each item and its corresponding dimension, and those between each dimension and its corresponding subscale were all greater than 0.4. The CFA supported the structure of SHMS V1.0 with strong factor loadings and excellent fit indexes in the firstorder and modified second-order factor model. The concurrent validity for SHMS V1.0 showed large correlation with FS-14, but social subscale showed medium correlations with total fatigue, physical fatigue and mental fatigue.

Conclusions The SHMS V1.0 is a valid and reliable instrument for measuring SHS for midwives. Given the severity and harmfulness of SHS in midwives, SHMS V1.0 is recommended as an important tool for clinical practice and research.

\section{Introduction}

Suboptimal health status (SHS) is an intermediate health status between health and illness. In traditional Chinese medicine (TCM) guidelines released by the China Association of Chinese Medicine, SHS is characterized as a decline in vitality, physiological function and the capacity for social adaptation, with no clear disease in clinical diagnosis [1]. The concept of SHS has been widely accepted in some other countries, including Japan, Ghana and Australia [2, 3], but it has not been clearly used in western countries. It seems that chronic fatigue is a more common concern in western countries, which is an individualized feeling of weakness, lack of energy and burnout, including physical and mental fatigue [4]. People with SHS without recognized and managed in time tend to suffer from chronic fatigue, headaches, dizziness, anxiety, depression, pain and functional disorders of organ systems, which can impair quality of life or work and finally lead to a series of diseases [5-7]. SHS is becoming a global health issue. The SHS prevalence took up $71.7 \%$ in nurses [8], $69.46 \%$ in Chinese adults [9] and $55.9 \%$ in Chinese students [10], and SHS had adverse effects on metabolic syndrome [3], cognitive impairment [7], oxidative stress in pregnant women [2]. Thus, it might be of great importance for medicine staff to early detect and prevent SHS resulting in chronic disease and other adverse impacts. 
As an integral part of healthcare professionals, midwives play an important role in ensuring and promoting the health of pregnant women and newborns [11]. Midwives are especially prone to SHS due to frequent rotating shift, shortage of human resources and high work stress [12-14]. Midwives have reported moderate to severe levels of exhaustion on $22-50 \%$ of all shifts and rest days [15], and there were $59.3 \%$ of midwives with SHS according to the TCM guidelines for SHS [16]. The United Nations Population Fund and the World Health Organization (WHO) have pointed out that there was a large shortage of midwives in the world [13]. Furthermore, the number of older mothers and obstetric complications has increased without a proportional increase in midwives since the opening of Chinese two-child policy [17], which makes midwives bear more work load and suffer from sleep disorders, fatigue, anxiety and burnout, and then accounts for lower job satisfaction, higher turnover and degradation in work quality [18-20]. Therefore, it is important to detect SHS among midwives for preventing it.

However, there is a lack of unified measurement standard for SHS. The diagnosis of SHS can be divided into subjective and objective measures, and the objective measurements for SHS such as blood pressure, pulse, lipid and plasma glycoprotein are still being explored [21, 22]. Subjective measurement is the main clinical diagnostics for SHS after excluding specific disease according to comprehensive physical examination [1]. SHS questionnaires have been developed and are widely used as diagnostic instruments of SHS in China, including Sub-Health Measurement Scale V1.0 (SHMS V1.0) [23], 36-item Short-Form Health Survey Questionnaire (SF-36) [24], and Suboptimal Health Status Questionnaire-25 (SHSQ-25) [25]. In particular, SHMS V1.0 is a multidimensional inventory that reports physiological, psychological and social symptoms [23], which is highly consistent with the WHO definition of health [26]. And SHMS V1.0 has been proved to have adequate psychometric properties in nurses (with Cronbach's alpha and split half reliability coefficient of $0.924,0.863$ ) [27], urban residents (with Cronbach's alpha and split half reliability coefficient of $0.928,0.847$ ) [28], and college students (with good construct validity) [29], which all indicate that it is a reliable and valid measurement scale for SHS. However, the reliability and validity of SHMS V1.0 in midwives are not known. Therefore, the aim of this study was to investigate the psychometric properties of SHMS V1.0 in midwives.

\section{Methods}

\section{Study design and participants}

A multi-centre cross-sectional study was conducted among midwives through stratified cluster random sampling in Fujian province of China from March to June 2019. The sample size was calculated based on the item numbers ( 35 items $\times 10=350$ ) [30]. Thus, the minimum sample size was 420 after considering a $20 \%$ non-response rate. The inclusion criteria for midwives were as follows: (1) obtained professional qualification certificates and work as independent position; (2) volunteer to participate in this study. The exclusion criteria were as follows: (1) took maternity leave or left their hospital for training for more than one month; (2) diagnosed as acute or chronic diseases. According to the annual report number of midwives in the province, 186 midwifery institutions with at least 5 midwives were selected in the study. 
Then total 900 participants eligible for inclusion were recruited from 37 secondary midwifery institutions and 9 tertiary midwifery institutions, which were randomly selected according to the proportion of secondary and tertiary midwifery institutions in the 186 midwifery institutions by computer-generated random numbers.

The study was approved by the ethical committee of the main researcher's hospital. Before the survey, oral informed consent was obtained from all nursing departments of the 46 hospitals and all participants.

\section{Measures}

Online questionnaires were used to collect the data in the study including socio-demographic questionnaire, SHMS V1.0 and the 14-item Fatigue Scale (FS-14). The socio-demographic questionnaire was designed by the researchers, including hospital nature, age, education level, years of midwifery experience, professional rank, professional position, marital status, and monthly income.

The SHMS V1.0, developed by Xu et al [23], is a self-reporting scale for providing assessment on health status during the past month. SHMS V1.0 consists of 39 items with three subscales: physiological subhealth (PS), mental sub-health (MS), social sub-health (SS), and 4 other items for overall evaluation of physiological, psychological, social and general health. PS comprises four dimensions: physical condition (P1) (three items), organ function (P2) (six items), body movement function (P3) (three items) and vitality (P4) (two items); MS comprises three dimensions: positive emotion (M1) (four items), psychological symptoms (M2) (six items) and cognitive function (M3) (two items); SS comprises two dimensions: social adaptability (S1) (four items), social resource and social support (S2) (five items). The 35 items were rated on a five-point Likert scale ( $1=$ never, $2=$ rarely, $3=$ sometimes, $4=$ often, $5=$ always), of which 15 items were reverse arranged. Total score for SHMS V1.0 was transformed to percentage score ranging from 0 to 100 , with the lower scores representing worse health status.

The FS-14 developed by Trudie Chalder et al [31] was used to measure the severity of participants' fatigue over the last month. FS-14 comprises 14 items with two dimensions: physical (items 1-8) and mental (items $9-14)$ fatigue. The scoring pattern for each item is a four-point Likert scale ( $0=$ less than usual, $1=$ no more than usual, $2=$ more than usual, $3=$ much more than usual). The total fatigue score obtained by adding up all items ranges from 0 to 42, with higher scores indicating more severe fatigue. The Chinese version of the FS-14 has been shown acceptable psychometric properties [32].

\section{Data collection}

The questionnaires survey was conducted through an online platform named "WenJuanXing"(미) which was used to make the survey link. Before the survey, the nurses in charge of labor wards in the 46 midwifery institutions were trained and informed of the purpose of the research, the requirements of choosing participants, the filling method and precautions of the questionnaire by phone. The main researcher sent the survey invitation and questionnaire link to those nurses in charge through Wechat 
which is an online communication platform. Then 46 nurses in charge selected the subjects according to the inclusion and exclusion criteria, explained the purpose of this study and the filling method of questionnaire, and sent the survey link to the eligible participants. All midwives who agreed to participate in the survey clicked on the survey link, completed and submitted the questionnaire. According to the data integrity of the "WenJuanXing" platform, this process was promoted by weekly reminders and data collection was completed after three reminders. Besides, 70 midwives were randomly selected and received the same tests again to investigate the test-retest reliability of SHMS V1.0 two weeks after the initial test.

\section{Data analysis}

All data were analyzed using the IBM SPSS 25.0 and IBM AMOS 24.0, which was used to conduct confirmatory factor analysis (CFA). Frequency, percentage, means and standard deviations (SD) were used to describe socio-demographic characteristics of midwives. For the reliability of SHMS V1.0, the internal consistency and test-retest reliability were performed by Cronbach's alpha coefficient and Pearson correlation coefficient, with values of at least 0.70 indicating acceptable reliability [33]. For the validity of SHMS V1.0, project analysis (item-total correlation) was used to test the homogeneity of each dimension and subscale, with the correlation coefficient greater than 0.40 considered as acceptable homogeneity [30]; the concurrent validity was evaluated by Pearson correlation analysis with FS-14, with the effect size as "Low" (the value of correlation coefficient varied around 0.1), "Medium" (the value of correlation coefficient varied around 0.30) and "Large" (the value of correlation coefficient varied more than 0.50) [34]; and the construct validity was performed by CFA, with the factor loadings being at least 0.40 indicating a sufficient correlation [35]. Good fit indexes for the models were indicated by the ratio between $\chi^{2}$ and the degrees of freedom of the model $\left(\chi^{2} / d f\right)$ less than 2, Root Mean Square Error of Approximation (RMSEA) less than 0.08, Incremental Fit Index (IFI), Tucker-Lewis index (TLI) or Comparative Fit Index (CFI) greater than 0.90, Parsimony Goodness-of-Fit Index (PGFI) greater than 0.50 $[30,36]$. All tests were two-sided and $p$-values less than 0.05 were regarded as statistically significant.

\section{Results}

A total of 900 midwives were eligible and invited to participate in the study, of which 842 completed all questionnaires, with 25 without submitting questionnaire and 33 unaccomplished questionnaires.

\section{Participant characteristics}

The participant socio-characteristics are shown in Table 1. Those midwives were from general (65.80\%), specialized $(28.15 \%)$ and private $(6.06 \%)$ hospital. The mean age of midwives was 31.41 years (SD = 6.42). Most midwives (54.16\%) had a junior college degree. Approximately half of midwives had less than five years of midwifery $(45.25 \%)$ and senior professional rank $(49.29 \%)$ with 58 nurses in charge (6.89\%). Most midwives were married $(71.85 \%)$ and $61.40 \%$ of midwives had monthly income ranging from 3000 to 5999RMB. 


\section{Reliability}

In terms of internal consistency of SHMS V1.0, the total Cronbach's alpha coefficient of the scale was 0.908. The Cronbach's alpha coefficients for physiological, psychological and social sub-health subscale were $0.714,0.893$ and 0.846 , respectively. In terms of test-retest reliability of SHMS V1.0, the Pearson correlation coefficient was 0.804 . The test-retest reliability for physiological, psychological and social sub-health subscale were $0.715(p<0.001), 0.861(p<0.001)$ and $0.503(p=0.010)$, respectively.

\section{Project analysis}

The results of project analysis are shown in Table 2 and Table 3. The correlation coefficients between each item and its associated dimension score ranged from 0.619 to 0.890 , higher than those between the item and other dimensions, which were all statistically significant $(p<0.01)$. The correlation coefficients between each dimension and its associated subscale score ranged from 0.614 to 0.911 , higher than those between the dimension and other subscales, which were all statistically significant $(p<0.01)$. The dimension-total correlations coefficients varied between 0.615 and 0.800 , which were statistically significant $(p<0.01)$.

\section{Confirmatory Factor Analysis}

The results of CFA including the first-order factor model, the second-order factor model and the modified second-order model are showed in Figure 1, Figure 2 and Figure 3. The fit indexes for CFA are showed in Table 4. For the first-order factor model, the loadings of each item in the corresponding dimension were greater than 0.4. The fit indexes revealed the following results: $\chi^{2} / d f$ was less than 2; RMSEA was less than 0.08; IFI, TLI and CFI were greater than 0.90; PGFI was greater than 0.50. For the second-order factor model, the loadings of each item in the corresponding dimension were greater than 0.4 and the loadings of each dimension in corresponding subscale were greater than 0.6 , but the model demonstrated no optimal fit indexes with $\chi^{2} / \mathrm{df}$ greater than 2 and TLI less than 0.90 . Based on modification indexes, two covariance factors between the errors for item 30 to 31 , and item 20 to 21 were added. The modified second-order factor model showed good model fit indexes with $\chi 2$ /df less than 2, RMSEA less than 0.08 , $\mathrm{IFI}, \mathrm{TLI}$ and CFI greater than 0.90 , PGFI greater than 0.50 .

\section{Concurrent validity}

Correlation analysis between SHMS V1.0 and FS-14 was shown in Table 5. Large negative correlations were observed between the scores of SHMS V1.0 and FS-14 including total fatigue $(r=-0.609, p<0.001)$, physical fatigue $(r=-0.594, p<0.001)$, mental fatigue $(r=-0.553, p<0.001)$. Physiological sub-health had large negative correlations with total fatigue and physical fatigue, and medium correlation with mental fatigue. Psychological sub-health had large negative correlations with total fatigue, physical fatigue and mental fatigue, while social sub-health showed medium correlations with FS-14.

\section{Discussion}


SHS has become a global public health challenge, but there is no unified diagnostic standard for it. Therefore, research on the evaluation method of SHS has attracted the attention of researchers. Many scales for SHS measurement have been developed in China, but some of them are either limited to traditional Chinese medical symptoms, or only focus on physiological indicators, which cannot reflect the connotation of SHS comprehensively. SHMS V1.0 was designed according to the definition of health from WHO, who defined health as a state of complete physiological, mental and social well-being and not merely the absence of disease or infirmity [26]. All items of SHMS V1.0 have been selected through Delphi expert consultation and field investigation [23], which would ensure the authority and practicability of the selected indexes. It can be concluded that SHMS V1.0 has good content validity. Thus, the purpose of this study was to evaluate the reliability and validity of SHMS V1.0 in midwives, in order to confirm whether SHMS V1.0 can accurately and reliably reflect the SHS of midwives for further research.

Reliability refers to the stability and consistency of a tool when it is used to investigate the same object. The present study showed that Cronbach's alpha coefficient for SHMS V1.0 was greater than 0.90 , which was considered as excellent internal consistency [34]. The Cronbach's alpha coefficient for three subscale of SHMS V1.0 were all greater than 0.70 , showing acceptable internal consistency. The test-retest coefficient for SHMS V1.0, physiological subscale and psychological subscale were all greater than 0.7 , indicating acceptable reliability, but that for social subscale was lower than 0.7 , maybe duo to small sample size for test-retest reliability. Overall, the overall reliability of SHMS V1.0 is good and it can evaluate SHS of midwives stably.

Validity refers to the matching degree between scale structure and measurement results, so as to evaluate the accuracy of the scale. In the study, the results of project analysis showed that the correlation coefficients between each item of SHMS V1.0 and its corresponding dimension, as well as those between each dimension and its corresponding subscale were all greater than 0.6 , indicating high homogeneity for each dimension and subscale; CFA showed that factor loadings in the first-order factor model and the second-order factor model were greater than 0.4 , which indicated that all items and dimensions of SHMS V1.0 were designed reasonably. Furthermore, all fit indexes for CFA in the first-order and modified secondorder factor model reached ideal values, showing good fitting effect of the models. In the modified second-order factor model, there was error correlation between item 20 and 21, consistent with the study of Cordova [37], which reported that spirit were associated with mood (Item 20: Do you feel nervous? Item 21: Do you feel bad or depressed?). There was also error correlation between item 30 and 31 in the modified model. Interpersonal relationship may lead to benefits in subjective well-being and performance [38]. Therefore, there are interacting effects between satisfaction with interpersonal relationships and performance in life, work or study (Item 30: Are you satisfied with your interpersonal relationship in society? Item 31: Are you satisfied with your performance in life, work and study?). Overall, the results illustrated that SHMS V1.0 had good construct validity among midwives.

Concurrent validity is to evaluate the effectiveness of the new tool by testing the correlation between new tool and reference standard. The present study took the FS-14 as a standard, which was used to measure physical and mental fatigue similar to SHS. Pearson correlation analysis showed strongly negative 
correlations between SHMS V1.0 and FS-14, but SS showed smaller correlations with FS-14 including total fatigue, physical fatigue and mental fatigue. Therefore, it can infer that SHMS V1.0 can more comprehensively reflect SHS of midwives than FS-14, especially for social health symptoms. Regarding PS, bad posture (bending and twisting) and standing for long periods during midwifery process make midwives physically tired [39]. Lack of sleep and biorhythm disorder which may be due to frequent rotating shifts work can also aggravate PS [20]. For MS, it takes much time, energy and emotion for midwives to deal with women's concerns and anxieties during the intrapartum period [40]. At the same time, high tension because of concerning the health of mothers and newborns, worrying about medical disputes, and facing further rescue in midwifery workplaces can easily lead to MS [41]. In regard to SS, Chinese midwives are subordinate to the nursing profession and there is no independent policy and professional system for midwives, which make them lack social recognition. In addition, most midwives are women who have more family responsibility than men, which weaken social support and social adaptation of professional women leading to SS [42]. Therefore, SHMS V1.0 is suitable for measuring the SHS of midwives

\section{Strengths and limitations}

The results of this study contribute to the limited research on the measurement of midwives' SHS. And it was the first and a multi-hospital study, with enough samples to evaluate the psychometric properties of SHMS V1.0 in midwives, which provides an inspiration for measuring SHS of midwives. Meanwhile, there are several limitations to this study. Firstly, the study was only conducted in one province of China, which might limit the generalizability to all Chinese midwives. Second, the races or characteristics of the sample usually affect the reliability and validity of questionnaires in general, so the universal applicability of SHMS V1.0 should be carefully considered.

\section{Conclusion}

The internal consistency coefficient and test-retest reliability coefficient showed SHMS V1.0 had acceptable reliability. Project analysis and CFA showed that SHMS V1.0 had good construct validity. The results of concurrent validity analysis indicated that SHMS V1.0 was an available tool to measure SHS of midwives including fatigue. In conclusion, SHMS V1.0 with excellent psychometric properties can accurately and reliably evaluate the SHS of midwives.

\section{Declarations}

\section{Author contributions}

All authors contributed to the study conception and design. Material preparation and data collection were performed by Xiao-Qian Chen, Qing-Xiang Zheng and Yu-Qing Pan, data analysis was performed by XinXin Huang and Gui-Hua Liu. The first draft of the manuscript was written by Xiao-Qian Chen, Xiu-Min 
Jiang and Qing-Xiang Zheng commented on previous versions of the manuscript. All authors read and approved the final manuscript.

\section{Conflict of Interest statement}

No conflict of interest has been declared by the authors.

\section{Acknowledgments}

We would be grateful to all of the 46 hospitals assisting us in recruiting participants for this study. We acknowledge 46 head nurses for assistance in collecting data. We thank all midwives who participated in the study.

\section{Funding Statement}

This study was supported by Social Development Guiding Project Fund from Fujian Science and Technology Department (No. 2019Y0059). The funder had no role in study design, data collection and analysis, decision to publish, or preparation of the manuscript.

\section{Availability of data and material}

Not applicable.

\section{Ethics approval}

The study was approved by the Ethical Committee of Fujian Maternal and Child Health Hospital, affiliated hospital of Fujian Medical University, China (No: 2018-206).

\section{Consent to participate}

Informed consent was obtained from all individual participants included in the study.

\section{References}

1. Wang, W., Russell, A., Yan, Y. (2014). Traditional Chinese medicine and new concepts of predictive, preventive and personalized medicine in diagnosis and treatment of suboptimal health. Epma $j$, 5(1),4. https://doi.org/10.1186/1878-5085-5-4.

2. Anto, E.O., Roberts, P., Coall, D.A., Adua, E., Turpin, C.A., Tawiah, A., et al. (2020). Suboptimal health pregnant women are associated with increased oxidative stress and unbalanced pro- and antiangiogenic growth mediators: a cross-sectional study in a Ghanaian population. Free radical research, 54(1),27-42. https://doi.org/10.1080/10715762.2019.1685668.

3. Adua, E., Memarian, E., Russell, A., Trbojević-Akmačić, I., Gudelj, I., Jurić, J., et al. (2019). Utilization of $\mathrm{N}$-glycosylation profiles as risk stratification biomarkers for suboptimal health status and metabolic 
syndrome in a Ghanaian population. Biomarkers in medicine, 13(15),1273-1287. https://doi.org/10.2217/bmm-2019-0005.

4. Shen, J., Barbera, J., Shapiro, C.M. (2006). Distinguishing sleepiness and fatigue: focus on definition and measurement. Sleep medicine reviews, 10(1),63-76. https://doi.org/10.1016/j.smrv.2005.05.004.

5. Schaefert, R., Hausteiner-Wiehle, C., Häuser, W., Ronel, J., Herrmann, M., Henningsen, P. (2012). Nonspecific, functional, and somatoform bodily complaints. Deutsches Arzteblatt international, 109(47),803-813. https://doi.org/10.3238/arztebl.2012.0803.

6. Chen, J., Xiang, H., Jiang, P., Yu, L., Jing, Y., Li, F., et al. (2017). The Role of Healthy Lifestyle in the Implementation of Regressing Suboptimal Health Status among College Students in China: A Nested Case-Control Study. International journal of environmental research and public health, 14(3). https://doi.org/10.3390/ijerph14030240.

7. Ding, G., Zhao, X., Wang, Y., Song, D., Chen, D., Deng, Y., et al. (2020). Evaluation of the relationship between cognitive impairment and suboptimal health status in a northern Chinese population: a cross-sectional study. Journal of global health, 10(1),010804. https://doi.org/10.7189/jogh.10.010804.

8. Xu, S.Y. (2013). The Study on Sub-Health Status and Associated Factors of Nurses in General Hospital in Guangzhou [Master], Southern Medical University.

9. Xu, T., Zhu, G., Han, S. (2020). Prevalence of Suboptimal Health Status and the Relationships between Suboptimal Health Status and Lifestyle Factors among Chinese Adults Using a Multi-Level Generalized Estimating Equation Model. International journal of environmental research and public health, 17(3). https://doi.org/10.3390/ijerph17030763.

10. Bi, J., Huang, Y., Xiao, Y., Cheng, J., Li, F., Wang, T., et al. (2014). Association of lifestyle factors and suboptimal health status: a cross-sectional study of Chinese students. BMJ open, 4(6),e005156. https://doi.org/10.1136/bmjopen-2014-005156.

11. Beal, M.W., Batzli, M.E., Hoyt, A. (2015). Regulation of Certified Nurse-Midwife Scope of Practice: Change in the Professional Practice Index, 2000 to 2015. Journal of midwifery \& women's health, 60(5),510-518. https://doi.org/10.1111/jmwh.12362.

12. Koblinsky, M., Moyer, C.A., Calvert, C., Campbell, J., Campbell, O.M.R., Feigl, A.B., et al. (2016). Quality maternity care for every woman, everywhere: a call to action. Lancet (London, England), 388(10057),2307-2320. https://doi.org/10.1016/S0140-6736(16)31333-2.

13. Day-Stirk, F., McConville, F., Campbell, J., Laski, L., Guerra-Arias, M., Hoope-Bender, P.T., et al. (2014). Delivering the evidence to improve the health of women and newborns: State of the World's Midwifery, report 2014. Reproductive health, 11,89. https://doi.org/10.1186/1742-4755-11-89.

14. Zhou, L.P., Pan, J.H., Cai, W.Z., Ruan, J., Yao, Y., Feng, Y.Q., et al. (2013). The relationship between subhealth status and organization environment in South China midwives Chinese Nursing Management, 13(10),55-58. https://doi.org/10.3969/j.issn.1672-1756.2013.010.020.

15. Tremaine, R., Dorrian, J., Paterson, J., Neall, A., Piggott, E., Grech, C., et al. (2013). Actigraph estimates of the sleep of Australian midwives: the impact of shift work. Biological research for nursing, 
15(2),191-199. https://doi.org/10.1177/1099800411422249.

16. Zhou, L.P., Pan, J.H., Cai, W.Z., Yuan, J., Yao, Y., Feng, Y.Q., et al. (2013). The relationship between subhealth status and organization environment in South China midwives. Chinese Nursing Management, 13(10),55-58. https://doi.org/10.3969/j.issn.1672-1756.2013.010.020.

17. Poston, L., Caleyachetty, R., Cnattingius, S., Corvalán, C., Uauy, R., Herring, S., et al. (2016). Preconceptional and maternal obesity: epidemiology and health consequences. The lancet. Diabetes \& endocrinology, 4(12),1025-1036. https://doi.org/10.1016/S2213-8587(16)30217-0.

18. Gu, C., Zhu, X., Ding, Y., Setterberg, S., Wang, X., Tao, H., et al. (2018). A qualitative study of nulliparous women's decision making on mode of delivery under China's two-child policy. Midwifery, 62. https://doi.org/10.1016/j.midw.2018.03.007.

19. Xiao, H.Y., Yu, J., Hu, F., Shen, S.Y., Xiao, W.Q., Xia, X.Y., et al. (2015). Short-and mid-term effects of obstetric human resources on obstetric quality. Maternal \& Child Health Care of China, 30(22),37653767. https://doi.org/10.7620/zgfybj.j.issn.1001-4411.2015.22.01.

20. Geiger-Brown, J., Trinkoff, A., Rogers, V.E. (2011). The impact of work schedules, home, and work demands on self-reported sleep in registered nurses. Journal of occupational and environmental medicine, 53(3),303-307. https://doi.org/10.1097/JOM.0b013e31820c3f87.

21. Yan, Y.-X., Dong, J., Liu, Y.-Q., Zhang, J., Song, M.-S., He, Y., et al. (2015). Association of suboptimal health status with psychosocial stress, plasma cortisol and mRNA expression of glucocorticoid receptor $\alpha / \beta$ in lymphocyte. Stress (Amsterdam, Netherlands), 18(1),29-34. https://doi.org/10.3109/10253890.2014.999233.

22. Kupaev, V., Borisov, O., Marutina, E., Yan, Y.-X., Wang, W. (2016). Integration of suboptimal health status and endothelial dysfunction as a new aspect for risk evaluation of cardiovascular disease. Epma j, 7(1),19. https://doi.org/10.1186/s13167-016-0068-0.

23. Xu, J., Feng, L.-y., Luo, R., Qiu, J.-C., Zhang, J.-h., Zhao, X.-s., et al. (2011). Assessment of the reliability and validity of the Sub-health Measurement Scale Version1.0. Nan fang yi ke da xue xue bao = Journal of Southern Medical University, 31(1),33-38.

24. Coulter, A., Entwistle, V.A., Eccles, A., Ryan, S., Shepperd, S., Perera, R. (2015). Personalised care planning for adults with chronic or long-term health conditions. The Cochrane database of systematic reviews, (3),CD010523. https://doi.org/10.1002/14651858.CD010523.pub2.

25. Wang, Y., Ge, S., Yan, Y., Wang, A., Zhao, Z., Yu, X., et al. (2016). China suboptimal health cohort study: rationale, design and baseline characteristics. Journal of translational medicine, 14(1),291. https://doi.org/10.1186/s12967-016-1046-y.

26. Organization, W.H. (2006). Constitution of the World Health Organization. Basic Documents, Fortyfifth edition, Supplement. http://www.who.int/governance/eb/who_constitution_en.pdf?ua=1. Accessed 1 May 2020.

27. Li, X.Y., Lu, Y., Zhang, Y.H., Yang, Y.S., Xu, J. (2012). Reliability and validity of Sub-Health Measurement Scale Version1.0 in evaluation of sub-Health of nurses. Journal of Nursing, 19(11),812. https://doi.org/10.3969/j.issn.1008-9969.2012.11.003. 
28. Lin, Y.Q., Xu, J., Li, W.Y., Wu, W.X., Xia, C. (2018). Reliability and validity of Sub-health Measurement Scale Version 1.0 for evaluating the sub-health status of Anhui urban residents. Chinese General Practice, 21(15),1845-1851. https://doi.org/10.3969/j.issn.1007-9572.2018.00.146.

29. Wang, Y.Y., Zhang, Y.N., Lin, S.Q., Yang, B.H. (2016). Factor analysis of Sub - Health Measurement Scale applied in college students in south of China. China Journal of Health Psychology, 24(11),1689-1692. https://doi.org/10.13342/j.cnki.cjhp.2016.11.023.

30. Xiao, X., Si, Y., Mo, Q., Liu, Y., Li, C., Zhao, J., et al. (2018). Development and validation of the Chinese Version of the Adult Epilepsy Self-Management Scale (C-ESMS) in Western China. Epilepsy research, 144,43-48. https://doi.org/10.1016/j.eplepsyres.2018.04.014.

31. Chalder, T., Berelowitz, G., Pawlikowska, T., Watts, L., Wessely, S., Wright, D., et al. (1993).

Development of a fatigue scale. Journal of psychosomatic research, 37(2),147-153. https://doi.org/10.1016/0022-3999(93)90081-p.

32. Wong, W.S., Fielding, R. (2010). Construct validity of the Chinese version of the Chalder Fatigue Scale in a Chinese community sample. Journal of psychosomatic research, 68(1),89-93. https://doi.org/10.1016/j.jpsychores.2009.05.008.

33. Pucciarelli, G., Årestedt, K., Simeone, S., Bolgeo, T., Alvaro, R., Vellone, E. (2020). Psychometric characteristics of the WHOQOL-SRPB Scale in a population of stroke survivors and caregivers. Quality of life research : an international journal of quality of life aspects of treatment, care and rehabilitation. https://doi.org/10.1007/s11136-020-02446-0.

34. Hwang, K.-S., Jang, S.-H., Lee, H.-J., Lee, S.-Y. (2018). Reliability and Validity of the Korean Version of Health Anxiety Questionnaire. Psychiatry investigation, 15(10),976-983. https://doi.org/10.30773/pi.2018.07.25.

35. Koller, M., Shamieh, O., Hjermstad, M.J., Hornslien, K., Young, T., Chalk, T., et al. (2020). Psychometric properties of the updated EORTC module for assessing quality of life in patients with lung cancer (QLQ-LC29): an international, observational field study. The Lancet. Oncology. https://doi.org/10.1016/S1470-2045(20)30093-0.

36. Terman, J.M., Awsumb, J.M., Cotler, J., Jason, L.A. (2018). Confirmatory factor analysis of a myalgic encephalomyelitis and chronic fatigue syndrome stigma scale. Journal of health psychology,1359105318796906. https://doi.org/10.1177/1359105318796906.

37. Cordova, M.J., Giese-Davis, J., Golant, M., Kronnenwetter, C., Chang, V., McFarlin, S., et al. (2003). Mood disturbance in community cancer support groups. The role of emotional suppression and fighting spirit. Journal of psychosomatic research, 55(5),461-467.

38. Mulfinger, N., Sander, A., Stuber, F., Brinster, R., Junne, F., Limprecht, R., et al. (2019). Clusterrandomised trial evaluating a complex intervention to improve mental health and well-being of employees working in hospital - a protocol for the SEEGEN trial. BMC public health, 19(1),1694. https://doi.org/10.1186/s12889-019-7909-4.

39. Younan, L., Clinton, M., Fares, S., Jardali, F.E., Samaha, H. (2019). The relationship between workrelated musculoskeletal disorders, chronic occupational fatigue, and work organization: A multi- 
hospital cross-sectional study. Journal of advanced nursing, 75(8),1667-1677.

https://doi.org/10.1111/jan.13952.

40. Hildingsson, I., Westlund, K., Wiklund, I. (2013). Burnout in Swedish midwives. Sexual \& reproductive healthcare : official journal of the Swedish Association of Midwives, 4(3),87-91.

https://doi.org/10.1016/j.srhc.2013.07.001.

41. Wang, H.M., Jia, J.J. (2013). Study on correlation among fatigue status, jop burnout and coping styles of midwives. Chinese General Practice Nursing, 11(30),2844-2846.

https://doi.org/10.3969/j.issn.1674-4748.2013.30.042.

42. Lian, Y., Xiao, J., Zhang, C., Guan, S., Li, F., Ge, H., et al. (2016). A comparison of the relationships between psychosocial factors, occupational strain, and work ability among 4 ethnic teacher groups in China. Archives of environmental \& occupational health, 71(2),74-84. https://doi.org/10.1080/19338244.2014.956859.

\section{Tables}


Table 1

Socio-demographic characteristics of the participants $(n=842)$

\begin{tabular}{|c|c|c|}
\hline Characteristics & $\mathbf{n}$ & $\%$ \\
\hline \multicolumn{3}{|l|}{ Hospital nature } \\
\hline General hospital & 554 & 65.80 \\
\hline Specialized hospital & 237 & 28.15 \\
\hline Private hospital & 51 & 6.06 \\
\hline \multicolumn{3}{|l|}{ Age (year) } \\
\hline$\leq 25$ & 123 & 14.61 \\
\hline $26-35$ & 531 & 63.06 \\
\hline $36-45$ & 156 & 18.53 \\
\hline$\geq 46$ & 32 & 3.80 \\
\hline \multicolumn{3}{|l|}{ Educational level } \\
\hline Technical secondary school degree & 70 & 8.31 \\
\hline Junior college degree & 456 & 54.16 \\
\hline Bachelor degree and above & 316 & 37.53 \\
\hline \multicolumn{3}{|l|}{ Years of midwifery experience (year) } \\
\hline$\leq 5$ & 381 & 45.25 \\
\hline $6-10$ & 225 & 26.72 \\
\hline $11-20$ & 181 & 21.50 \\
\hline$\geq 21$ & 55 & 6.53 \\
\hline \multicolumn{3}{|l|}{ Professional rank } \\
\hline Junior nurse & 213 & 25.30 \\
\hline Senior nurse & 415 & 49.29 \\
\hline Assistant advanced nurse & 185 & 21.97 \\
\hline Associate advanced nurses or Advanced nurses & 29 & 3.44 \\
\hline \multicolumn{3}{|l|}{ Professional position } \\
\hline Nurse in charge & 58 & 6.89 \\
\hline Midwife & 784 & 93.11 \\
\hline
\end{tabular}




\begin{tabular}{|lll|}
\hline Characteristics & $\mathbf{n}$ & $\mathbf{\%}$ \\
\hline Unmarried & 237 & 28.15 \\
\hline Married & 605 & 71.85 \\
\hline Monthly income (RMB) & & \\
\hline$<3000$ & 84 & 9.98 \\
\hline $3000-5999$ & 517 & 61.40 \\
\hline $6000-8999$ & 164 & 19.48 \\
\hline$\geq 9000$ & 77 & 9.14 \\
\hline
\end{tabular}


Table 2

Correlation between item and dimension score of SHMS V1.0 ( $r$ )

Items Dimensions

$\begin{array}{lllllllll}\text { P1 } & \text { P2 } & \text { P3 } & \text { P4 } & \text { M1 } & \text { M2 } & \text { M3 } & \text { S1 } & \text { S2 }\end{array}$

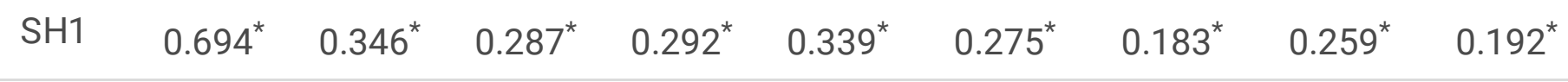

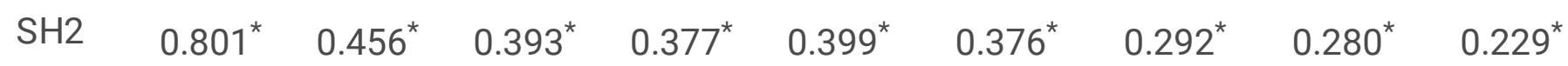

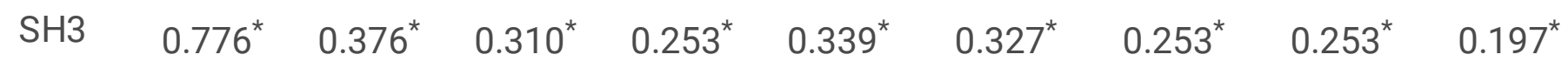

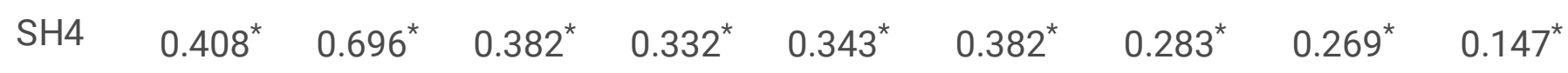

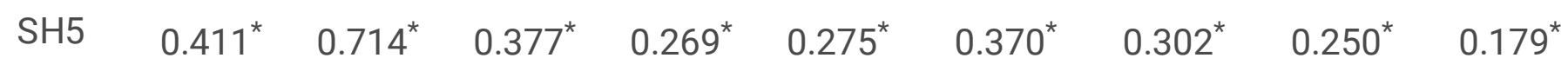

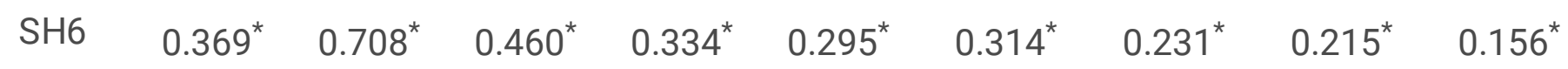

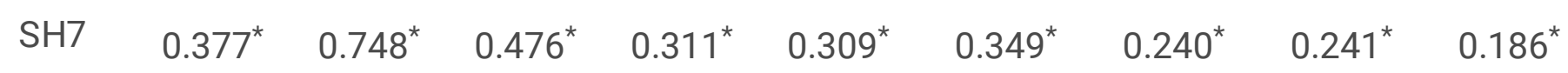

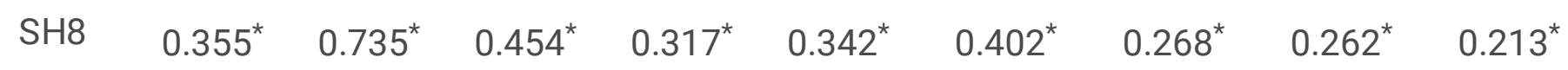

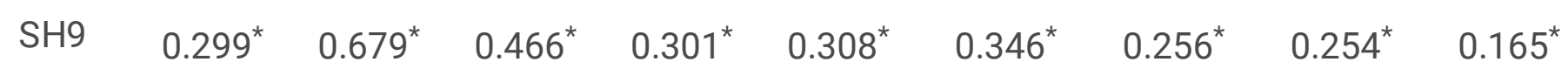

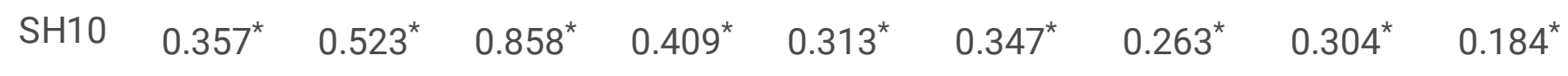

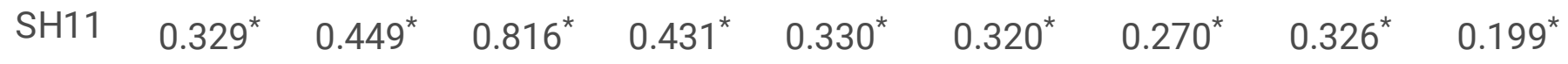

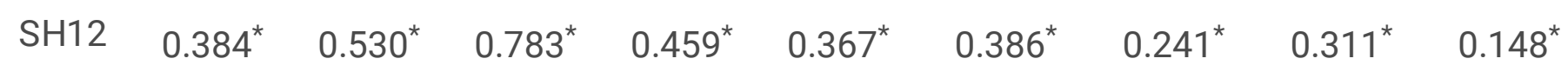

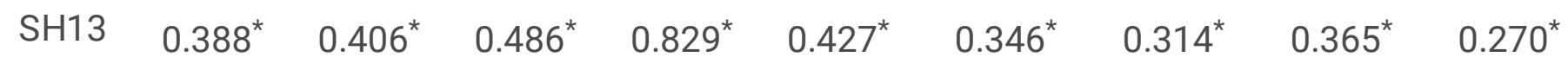

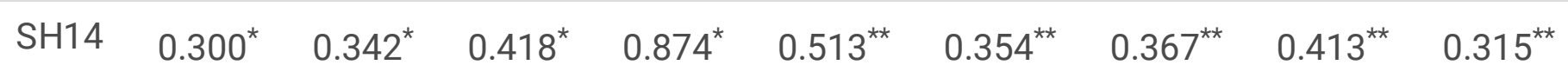

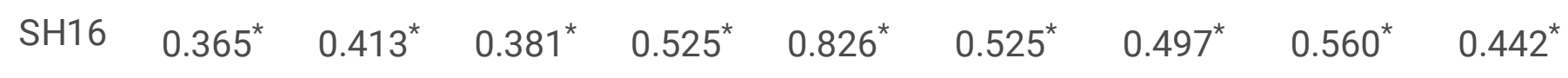

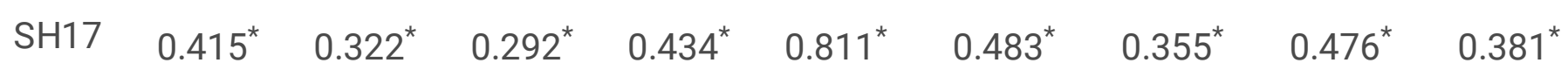

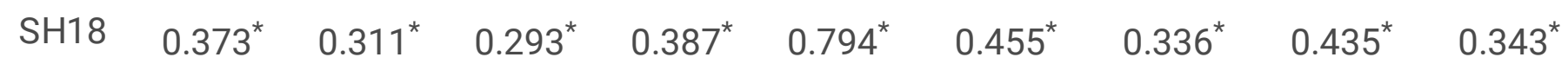

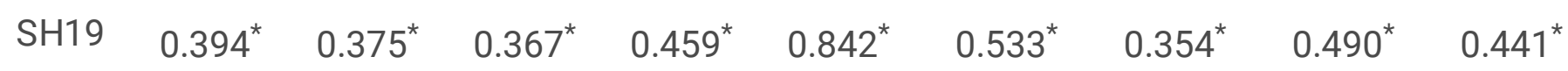

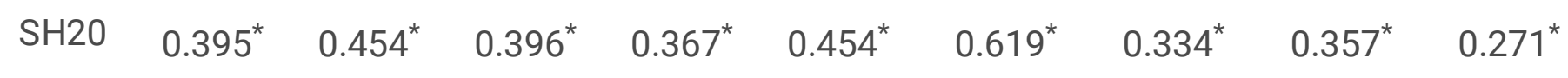

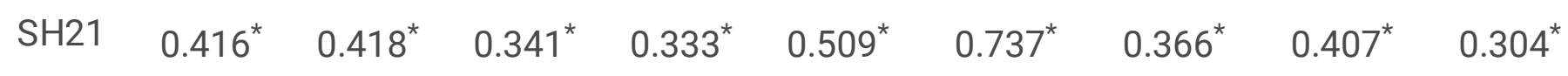

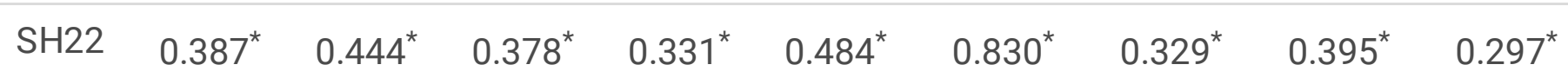

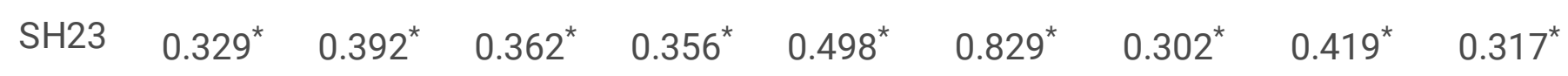




\begin{tabular}{|c|c|c|c|c|c|c|c|c|c|}
\hline \multirow[t]{2}{*}{ Items } & \multicolumn{9}{|c|}{ Dimensions } \\
\hline & P1 & P2 & P3 & P4 & M1 & M2 & M3 & S1 & $\mathrm{S} 2$ \\
\hline $\mathrm{SH} 24$ & $0.320^{*}$ & $0.406^{*}$ & $0.335^{*}$ & $0.339^{*}$ & $0.518^{*}$ & $0.808^{*}$ & $0.326^{*}$ & $0.444^{*}$ & $0.397^{*}$ \\
\hline $\mathrm{SH} 25$ & $0.285^{\star}$ & $0.351^{*}$ & $0.286^{*}$ & $0.272^{*}$ & $0.419^{*}$ & $0.753^{*}$ & $0.288^{*}$ & $0.402^{*}$ & $0.299^{*}$ \\
\hline $\mathrm{SH} 26$ & $0.316^{*}$ & $0.371^{*}$ & $0.333^{*}$ & $0.396^{*}$ & $0.419^{*}$ & $0.367^{\star}$ & $0.890^{\star}$ & $0.404^{*}$ & $0.342^{*}$ \\
\hline SH27 & $0.230^{*}$ & $0.244^{*}$ & $0.186^{*}$ & $0.276^{*}$ & $0.391^{*}$ & $0.317^{\star}$ & $0.811^{*}$ & $0.556^{*}$ & $0.400^{\star}$ \\
\hline $\mathrm{SH} 29$ & $0.260^{*}$ & $0.283^{*}$ & $0.330^{*}$ & $0.399^{*}$ & $0.459^{*}$ & $0.457^{*}$ & $0.387^{*}$ & $0.788^{* *}$ & $0.381^{*}$ \\
\hline SH30 & $0.322^{*}$ & $0.278^{*}$ & $0.289^{*}$ & $0.344^{*}$ & $0.509^{*}$ & $0.422^{*}$ & $0.493^{*}$ & $0.814^{*}$ & $0.469^{*}$ \\
\hline SH31 & $0.265^{*}$ & $0.265^{\star}$ & $0.248^{*}$ & $0.304^{*}$ & $0.525^{\star}$ & $0.401^{*}$ & $0.473^{*}$ & $0.835^{*}$ & $0.400^{\star}$ \\
\hline SH32 & $0.279^{*}$ & $0.306^{*}$ & $0.374^{*}$ & $0.439^{*}$ & $0.468^{*}$ & $0.419^{*}$ & $0.439^{*}$ & $0.817^{\star}$ & $0.436^{*}$ \\
\hline SH33 & $0.210^{\star}$ & $0.256^{*}$ & $0.230^{*}$ & $0.281^{*}$ & $0.419^{*}$ & $0.353^{*}$ & $0.362^{*}$ & $0.419^{*}$ & $0.735^{\star}$ \\
\hline SH34 & $0.213^{*}$ & $0.177^{\star}$ & $0.137^{*}$ & $0.214^{\star}$ & $0.349^{*}$ & $0.300^{*}$ & $0.331^{*}$ & $0.389^{*}$ & $0.808^{*}$ \\
\hline SH35 & $0.232^{*}$ & $0.217^{\star}$ & $0.160^{*}$ & $0.269^{*}$ & $0.385^{\star}$ & $0.325^{*}$ & $0.381^{*}$ & $0.438^{*}$ & $0.821^{*}$ \\
\hline SH36 & $0.195^{\star}$ & $0.143^{*}$ & $0.159^{*}$ & $0.306^{*}$ & $0.373^{*}$ & $0.308^{*}$ & $0.295^{*}$ & $0.414^{*}$ & $0.691^{*}$ \\
\hline SH37 & $0.146^{*}$ & $0.097^{*}$ & $0.102^{*}$ & $0.204^{*}$ & $0.291^{*}$ & $0.217^{\star}$ & $0.203^{*}$ & $0.244^{*}$ & $0.623^{*}$ \\
\hline
\end{tabular}


Table 3

Correlation between dimension and subscale score of SHMS V1.0 (r)

\begin{tabular}{|lllll|}
\hline Dimensions & physiological, sub-health & psychological sub-health & $\begin{array}{l}\text { social } \\
\text { sub-health }\end{array}$ & sub-health \\
\hline P1 & $0.723^{*}$ & $0.518^{*}$ & $0.346^{*}$ & $0.653^{*}$ \\
\hline P2 & $0.894^{*}$ & $0.553^{*}$ & $0.330^{*}$ & $0.744^{*}$ \\
\hline P3 & $0.810^{*}$ & $0.488^{*}$ & $0.327^{*}$ & $0.677^{*}$ \\
\hline P4 & $0.674^{*}$ & $0.554^{*}$ & $0.449^{*}$ & $0.674^{*}$ \\
\hline M1 & $0.569^{*}$ & $0.868^{*}$ & $0.617^{*}$ & $0.800^{*}$ \\
\hline M2 & $0.569^{*}$ & $0.897^{*}$ & $0.523^{*}$ & $0.785^{*}$ \\
\hline M3 & $0.439^{*}$ & $0.614^{*}$ & $0.549^{*}$ & $0.615^{*}$ \\
\hline S1 & $0.465^{*}$ & $0.653^{*}$ & $0.825^{*}$ & $0.722^{*}$ \\
\hline S2 & $0.323^{*}$ & $0.520^{*}$ & $0.911^{*}$ & $0.624^{*}$ \\
\hline$* p<0.01$ & & & & \\
\hline
\end{tabular}

Table 4

The fit indexes for confirmatory factor analysis

\begin{tabular}{|lllllll|}
\hline Fit index & $\chi^{2} \chi^{2} / d f$ & RMSEA & IFI & TLI & CFI & PGFI \\
\hline Thresholds for good fit & $<2.00$ & $<0.08$ & $>0.90$ & $>0.90$ & $>0.90$ & $>0.50$ \\
\hline The first-order factor model & 1.958 & 0.048 & 0.919 & 0.907 & 0.918 & 0.726 \\
\hline The second-order factor model & 2.087 & 0.051 & 0.903 & 0.894 & 0.902 & 0.750 \\
\hline The modified second-order factor model & 1.955 & 0.048 & 0.915 & 0.907 & 0.915 & 0.757 \\
\hline
\end{tabular}


Table 5

Correlation between the scores of SHMS V1.0 and FS-14 (r)

\begin{tabular}{|c|c|c|c|c|}
\hline & $\begin{array}{l}\text { sub- } \\
\text { health }\end{array}$ & $\begin{array}{l}\text { physiological, sub- } \\
\text { health }\end{array}$ & $\begin{array}{l}\text { psychological sub- } \\
\text { health }\end{array}$ & $\begin{array}{l}\text { social sub- } \\
\text { health }\end{array}$ \\
\hline Total Fatigue & $-0.609^{\star *}$ & $-0.526^{\star *}$ & $-0.591^{\star *}$ & $-0.406^{\star *}$ \\
\hline $\begin{array}{l}\text { Physical } \\
\text { Fatigue }\end{array}$ & $-0.594^{\star \star}$ & $-0.517^{\star \star}$ & $-0.577^{\star \star}$ & $-0.393^{\star \star}$ \\
\hline Mental Fatigue & $-0.553^{\star \star}$ & $-0.474^{\star *}$ & $-0.538^{\star \star}$ & $-0.374^{\star *}$ \\
\hline
\end{tabular}

\section{Figures}




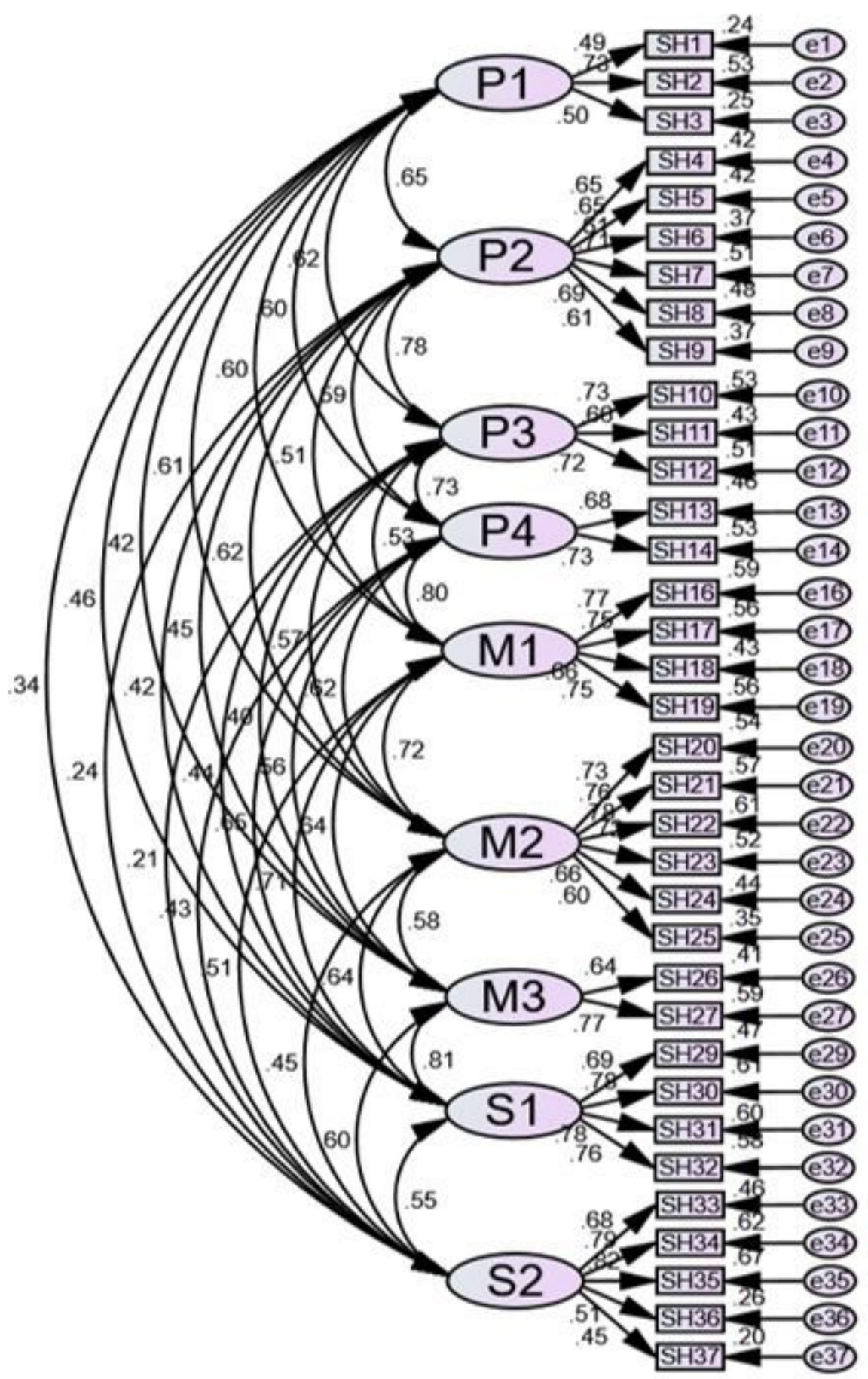

Figure 1

The first-order factor analysis for SHMS V1.0 


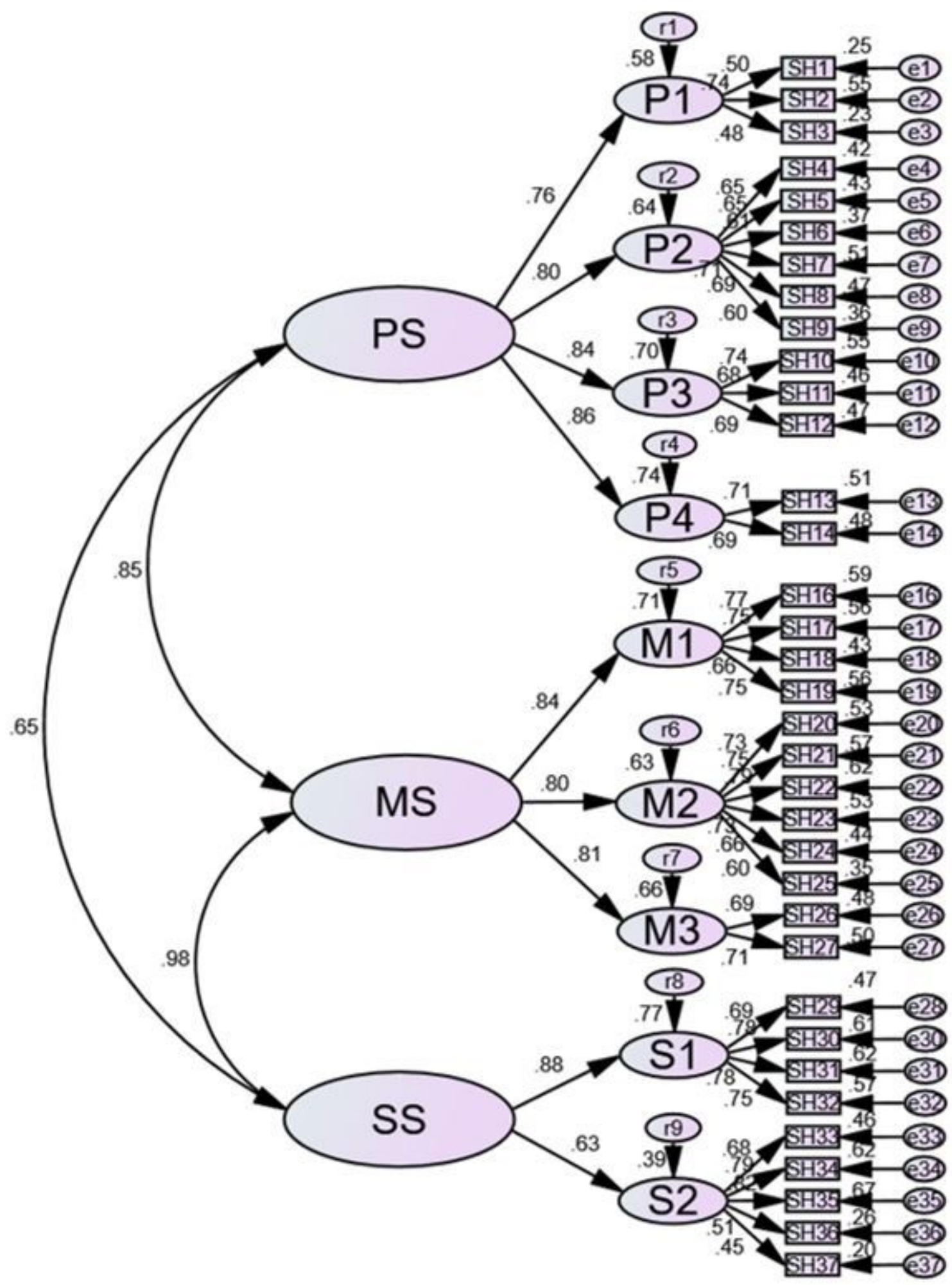

Figure 2

The second-order factor analysis for SHMS V1.0 


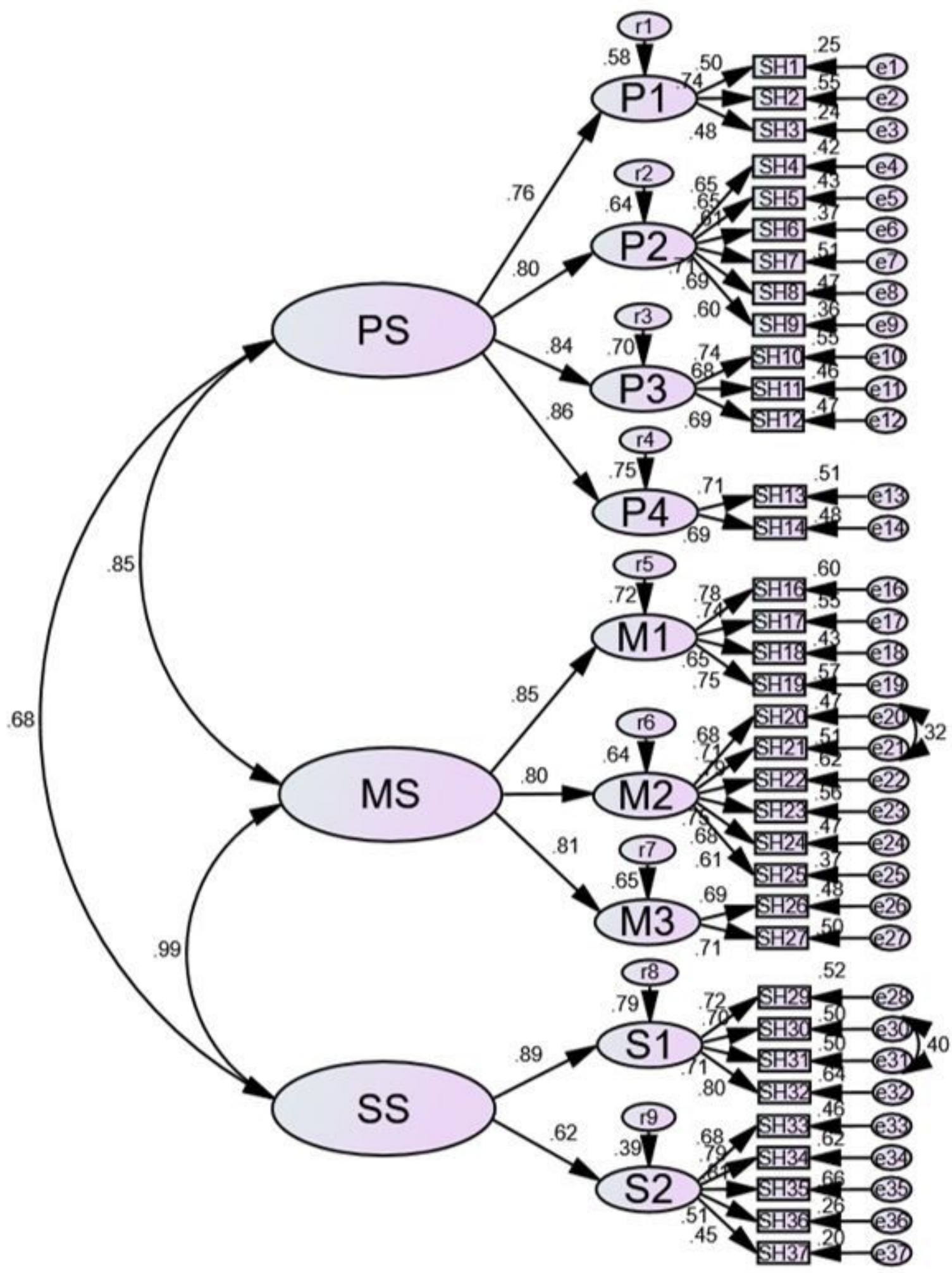

Figure 3

The modified second-order factor analysis for SHMS V1.0

\section{Supplementary Files}

This is a list of supplementary files associated with this preprint. Click to download. 
- PlainEnglishsummary.docx

Page 23/23 